\title{
12 item Allodynia Symptom Checklist/Brasil: cross-cultural adaptation, internal consistency and reproducibility
}

\author{
12 item Allodynia Symptom Checklist/Brasil: adaptação transcultural, consistência \\ interna e reprodutibilidade
}

Lidiane Lima Florencio', Thais Cristina Chaves², Livia B. Branisso³, Maria Cláudia Gonçalves", Fabíola Dach5, José Geraldo Speciali6, Marcelo Eduardo Bigal7, Débora Bevilaqua-Grossi

\begin{abstract}
Since there was no Portuguese questionnaire to evaluate cutaneous allodynia, which has been pointed out as a risk factor of migraine, we aimed to perform the cross-cultural adaptation of the 12 item Allodynia Symptom Checklist for the Brazilian population and to test its measurement properties. It consisted in six stages: translation, synthesis, back translation, revision by a specialist committee, pretest and submission the documents to the committee. In the pretest stage, the questionnaire was applied to 30 migraineurs of both sexes, who had some difficulty in understanding it. Thus, a second version was applied to 30 additional subjects, with no difficulties being reported. The mean filling out time was 3'36", and the internal consistency was 0.76. To test reproducibility, 15 other subjects filled out the questionnaire at two different times, it was classified as moderate (weighted kappa=0.58). We made available to Brazilian population an easy, quick and reliable questionnaire.
\end{abstract}

Key words: translating, reproducibility of results, internal consistency, allodynia, migraine.

\section{RESUMO}

Levando em consideração que não há nenhum questionário em português disponível para avaliação da alodinia cutânea, sintoma que tem sido apontado como fator de cronificação da migrânea, o objetivo do trabalho foi realizar a adaptação transcultural do 12 item Allodynia Symptom Checklist para a população brasileira e testar suas características psicométricas. A adaptação foi realizada em seis estágios: tradução, síntese, retrotradução, revisão pelo comitê de especialistas, pré-teste e submissão dos documentos ao comitê. No estágio do pré-teste, foram aplicados 30 questionários em migranosos de ambos os sexos, que relataram dificuldades de compreensão. Por isso, foi criada uma segunda versão e aplicada a mais 30 sujeitos, não tendo sido relatadas dificuldades nesta versão. 0 tempo médio de preenchimento foi de 3'36", e a consistência interna encontrada foi 0,76. Para testar a reprodutibilidade, outros 15 sujeitos preencheram o questionário, em dois momentos, tendo sido a reprodutibilidade classificada como moderada (kappa ponderado=0,58). Portanto, disponibilizamos, para uso na população brasileira, um questionário fácil, rápido e confiável.

Palavras-Chave: tradução, reprodutibilidade dos testes, consistência interna, alodinia, enxaqueca.

Hospital das Clínicas da Faculdade de Medicina de Ribeirão Preto da Universidade de São Paulo (HCFMRP-USP), Ribeirão Preto SP, Brazil.

'Physiotherapist, Master's student, Health Sciences Applied to the Locomotor Apparatus, Faculdade de Medicina de Ribeirão Preto, Universidade de São Paulo (FMRP-USP), Ribeirão Preto SP, Brazil;

${ }^{2}$ Physiotherapist, PhD, Assistant Professor, Department of Neurosciences and Behavioral Sciences, FMRP-USP, Ribeirão Preto SP, Brazil;

${ }^{3}$ Physical Therapy Graduation Student, FMRP-USP, Ribeirão Preto SP, Brazil;

4Physiotherapist, MD, Doctorate's student in Health Sciences Applied to the Locomotor Apparatus, FMRP-USP, Ribeirão Preto SP, Brazil;

${ }^{5}$ Neurologist, PhD, Hospital das Clínicas da Faculdade de Medicine de Ribeirão Preto, Universidade de São Paulo (HCFMRP-USP), Ribeirão Preto SP, Brazil;

${ }^{6}$ Neurologist, PhD, Assistant Professor, Department of Neurosciences and Behavioral Sciences, FMRP-USP, Ribeirão Preto SP, Brazil;

${ }^{7}$ Neurologist, PhD, Head of the Merck Investigator Study Program, Scientific Engagement and Education (MISP/SEE), North Wales, USA;

${ }^{8}$ Physiotherapist, PhD, Assistant Professor, Department of Biomechanics, Medicine and Rehabilitation of the Locomotor Apparatus, FMRP-USP, Ribeirão Preto SP, Brazil.

Correspondence: Lidiane Lima Florencio; Faculdade de Medicina de Ribeirão Preto; Avenida Bandeirantes 3900; 14049 -900 Ribeirão Preto SP - Brasil; E-mail: lidiane.florencio@usp.br

Support: Fundação de Amparo à Pesquisa do Estado de São Paulo (FAPESP) as a scholarship provided for the first author and the translation fee provided by Fundação de Apoio ao Ensino, Pesquisa e Assistência of HCFMRP (FAEPA).

Conflict of interest: There is no conflict of interest to declare.

Received 02 April 2012; Received in final form 07 May 2012; Accepted 14 May 2012 
Cutaneous allodynia (CA), defined as pain in response to a non-nociceptive stimulus ${ }^{1}$ when the stimulus is applied to normal skin $^{2}$, has been attracting more interest by having been recognized as a signal of central sensitization during migraine attacks ${ }^{3-5}$ and having been suggested as a risk factor for migraine chronification ${ }^{2,6,7}$. The relation of CA with migraine is believed to be due to a change in the central modulation of nociceptive pathways ${ }^{8}$ because of central sensitization, which provokes hyperexcitability of first-, second- and third-order neurons respectively located at the periphery, in the caudal nucleus of the trigeminus and in the thalamus ${ }^{5,9}$.

Clinical and population studies have reported that CA affects approximately two thirds of migraine patients ${ }^{9,10}$ and have pointed out as risk factors for its development female sex, obesity, depression, temporomandibular disorders and greater severity and frequency of attacks ${ }^{6,10,11}$. In addition, it has been suggested that CA can have a negative influence on the response to treatment with triptans ${ }^{12}$. Thus, we may state that the identification of CA in migraine patients is important for the choice of treatment for the establishment of the prognosis of the disease.

The gold standard for an objective and quantitative evaluation of CA during specific periods is the Quantitative Sensory Test $(\mathrm{QST})^{6}$, a tool capable of evaluating the pain threshold for thermal and mechanical stimuli extensively used in patients with sensory symptoms of central and peripheral origin ${ }^{13,14}$. However, since the application of the QST requires specialized equipment and training of the rater ${ }^{10}$, despite its efficacy, its use is expensive and at times not viable in clinical routine and in epidemiological studies ${ }^{6,10}$.

An alternative to this impasse is the application of reliable questionnaires, which are simple and rapid tools. Among the available options, particularly outstanding is the 12 item Allodynia Symptom Checklist (ASC-12), a questionnaire with excellent psychometric characteristics ${ }^{15}$ which has been already validated with respect to the QST. This questionnaire consists of 12 questions and permits the identification of CA and its classification in terms of the degree of severity.

In Brazil, no questionnaire aiming at the evaluation of CA is currently available in the Portuguese language, and the QST is not an usual evaluation. Since the prevalence of migraine in Brazilian population is about $15 \%^{16}$, the assessment of CA cannot be overlooked.

The cross-cultural adaptation of the ASC-12 permitted us to obtain a tool with the same content validity as the original questionnaire ${ }^{17}$ and to compare the data collected crossculturally ${ }^{18}$. To achieve a good adaptation, it is important to be rigorous in the process, include assessments of the quality of the translation and describe meticulously the translation process allowing readers to assess the rigor and quality of the tool ${ }^{18}$. However, this process does not guarantee the same validity and reliability of the original questionnaire and, therefore, other tests are needed in order to assess the psychometric properties of the adapted version ${ }^{19}$.
Thus, our objective was to perform the cross-cultural adaptation of the ASC-12 to the Portuguese language since this is a questionnaire that has already been validated for the assessment of CA. As a secondary objective, we evaluated some measurement properties: the internal consistency and the reproducibility of this version. Our intention was to obtain a questionnaire capable of diagnosing and classifying allodynia in the Brazilian population in order to facilitate the identification of this symptom both in clinical practice and in clinical and population studies in a reliable and rapid manner.

\section{METHODS}

\section{Cross-cultural adaptation}

The cross-cultural adaptation of the ASC-12 was carried out according to a protocol suggested in the literature ${ }^{20}$, with the consent of the authors of the original questionnaire and the approval of the Research Ethics Committee of the Hospital das Clínicas da Faculdade de Medicina de Ribeirão Preto, Universidade de São Paulo (HCFMRP-USP).

The process of cross-cultural adaptation consisted of six stages:

- Stage I - initial translation: carried out by two translators, the first one being aware of the concepts evaluated in questionnaire, with his translation (T1) representing the clinical equivalence, whereas the second translator was unaware of the concepts and his translation (T2) represented the popular language.

- $\quad$ Stage II - synthesis of the initial translations: a meeting between the investigator in charge and the translators, in which a common translated version was elaborated (T12).

- $\quad$ Stage III - back translation: in this stage, T12 was translated by two native English speakers who were fluent in Portuguese. Neither one had previous knowledge of the original questionnaire or of the concepts evaluated. Versions BT1 and BT2 were generated.

- Stage IV - revision by a specialist committee: the committee consisted of eight members, two of them neurologists, one of them co-author of the original version, two physiotherapists with previous knowledge of allodynia, a translator of Stage I (the second could not be present), the two back translators and the investigator in charge. The first translated version (TV1) was elaborated in this stage by means of a discussion of all the previous versions developed (T1, T2, T12, BT1 and BT2).

- Stage V - test of the pre-final version: the version elaborated in the previous stage was applied to 30 subjects of both sexes with migraine, with 5 to 12 days of headache per month. The subjects were attended at headache outpatient clinics providing secondary and tertiary care and gave written informed consent to participate in the study. Subjects 
who did not fulfill the above inclusion criteria were excluded, as also were subjects with other types of headache, fibromyalgia, neuralgia of the trigeminus or other diseases causing sensitive peripheral neuropathy. Since there was difficulty in understanding the first version, a second version (TV2) was elaborated by the same committee in order to solve the impasses detected (Table 1). This version was then applied to 30 other subjects with the same characteristics as the previous group. The only difficulty, reported by three subjects in this second group was to confuse the option "It does not apply to me" with "No, never". Because the choice between the two options does not change the ASC12 score, the group opted not to modify the questionnaire again. Thus, the Brazilian version of the ASC-12 was created, named by the committee 12 item Allodynia Symptom Checklist/Brasil (ASC-12/Brasil).

- Stage VI - submission of the documents to the committee: all stages were recorded in writing and, after verification by the committee, were sent to the person responsible for the original questionnaire in order to confirm that all the stages of the process had been properly fulfilled.

\section{Internal consistency}

The internal consistency is a measure of the degree of the interrelatedness of the questionnaire items, thus measuring the same concept ${ }^{21,22}$. It was determinate for ASC-12/ Brasil, based on the sample of the TV2, by the Cronbach's $\alpha$ using the SAS/STAT version 9, with values between 0.7 and 0.95 being considered positive results. A low Cronbach's $\alpha$ indicates a lack of correlation between the items, and a very high value indicates its redundancy ${ }^{22}$.

\section{Reproducibility}

The term reproducibility is related to the extent to which a tool for evaluation is able to reproduce the results in testretest situations within the same conditions ${ }^{23}$.

To test the reproducibility of the adapted version, 15 additional individuals were evaluated using the same inclusion and exclusion criteria as in the above pretest. The sample was recruited from employees of HCFMRP who had been diagnosed as migraineurs by neurologists. The study was approved by the Research Ethics Committee of HCFMRP and both the person responsible for the application of the questionnaire and the subjects recruited gave written informed consent to participate in the study. An examiner instructed each subject about answering the questionnaire, which was filled out immediately and then again 4 to 24 hours later according to the availability of the participant.

The results were obtained using the weighted kappa coefficient and analyzed by the SPSS version 14, and reproducibility was classified as follows according to Landis and $\mathrm{Koch}^{24}:<0.20$ (poor), 0.21 to 0.40 (weak), 0.41 to 0.60 (moderate), 0.61 to 0.80 (good), 0.81 to 1.0 (excellent).
Table 1. Frequency of doubts and difficulties reported during the application of the two versions elaborated during the pretest stage of transcultural adaptation of the 12 item Allodynia Symptom Checklist (ASC-12).

\begin{tabular}{lcc} 
& $\begin{array}{c}\text { Translated } \\
\text { version 1 }\end{array}$ & $\begin{array}{c}\text { Translated } \\
\text { version 2 }\end{array}$ \\
\hline $\begin{array}{l}\text { Difficulty in accompanying lines } \\
\text { and columns }\end{array}$ & 7 & 0 \\
$\begin{array}{l}\text { The respondent confused the option } \\
\text { "It does not apply to me" with "No, never" }\end{array}$ & 4 & 3 \\
$\begin{array}{l}\text { Difficulty in choosing the replies } \\
\text { The respondent did not understand the } \\
\text { option "Sometimes yes, sometimes no" }\end{array}$ & 2 & 0 \\
$\begin{array}{l}\text { The respondent found the letter size to } \\
\text { small }\end{array}$ & 1 & 0 \\
$\begin{array}{l}\text { The respondents had no doubts or } \\
\text { difficulties }\end{array}$ & 15 & 0 \\
Total & 30 & 30 \\
\hline
\end{tabular}

\section{RESULTS}

Of the 30 subjects in group TV1, mean age 43 years ( $\mathrm{SD}=4.95)$, only 2 were males. Regarding schooling, 9 had completed elementary school, 4 had incomplete elementary education, 14 had completed high school, 1 was enrolled in higher education and 2 had completed it. The mean time needed to fill out TV1 was 4 minutes ( $\mathrm{SD}=2.23$ ).

In the TV2 group, mean age was 36 years (SD=7.07) and 4 subjects were males. Eleven had incomplete elementary education, 2 had incomplete high school education, 3 had completed high school, 3 were enrolled in higher education and 1 had completed it. The mean time needed to fill out TV2 was 3 minutes and 36 seconds ( $\mathrm{SD}=2.38$ ).

Since no question was removed, the score and the classification of ASC-12/Brasil were the same, as follows: "It does not apply to me", "No, never" and "Rarely" (0 points), "At times yes and at times no" (1 point) and "Most of the times" (2 points); without allodynia (0-2) or with mild (3-5), moderate (6-8) or severe allodynia (9 or more) $)^{4}$. Although it appears to be an erroneous translation of the English term "severe", the term "severa" was chosen to classify instead of "grave", because, although the two terms are synonyms, the second denotes a risk of fatality within the spectrum of the Brazilianportuguese health conceptions ${ }^{25}$.

The questions showing higher scores, representing a higher frequency of the symptom reported, were questions 1 (66 points), 2 (63 points), 10 and 11 (61 points each) (Table 2).

The internal consistency of the questionnaire was 0.76 , and the values for each question ranged from 0.72 to 0.80 (Table 2).

Regarding reproducibility, of the 15 subjects tested, 14 were females, with a mean age of 40 years $(\mathrm{SD}=8)$. According to the weighted kappa, the reliability of the total score of the questionnaire was considered to be moderate (0.58), and the reliability of each question ranged from moderate to excellent (0.42-1) (Table 2). 
The characteristics of headache, such as time of disease, presence of pain during the evaluation, pain intensity and frequency of attacks in both groups (TV1 and TV2), did not show association with the score obtained for the ASC-12/Brasil when determined by the Fisher exact test (Table 3).

According to the classification of the ASC-12/Brasil, 76\% of the subjects evaluated in the present study have allodynia, severe in $30 \%$ of them, moderate in $23 \%$ and mild in $23 \%$. Twenty-four percent of the subjects have no allodynia.

\section{DISCUSSION}

The process of cross-cultural adaptation should be judicious in order to guarantee the quality of the data obtained with the translated version. It should also maintain the validity of the content in relation to the original concept when the tool is applied to different cultures ${ }^{17}$, as well as help standardize the evaluations and globalize the results reported in the literature ${ }^{26}$. The present study followed a protocol of cross-cultural adaptation recommended in the literature ${ }^{20}$ and resulted in the ASC-12/Brasil, a questionnaire that can identify and classify a symptom that is highly prevalent in the population ${ }^{10}$, with high clinical repercussions.

The committee review of the translations and back translations aimed to achieve the semantic and idiomatic equivalence defined as the similarity of the meaning of words and equivalent expressions respectively ${ }^{17}$. Additional attention was given for the conceptual equivalence when the terms used in the classification were chosen, since items available were equivalent semantically, but not conceptually ${ }^{17}$. Considering there were no changes in norm of the scores and its classification, the criterion equivalence ${ }^{27}$ was also achieved.

In the present study, CA was detected in $76 \%$ of the participants, being classified as severe in $39 \%$ of them. This is a higher estimate than previously reported frequencies, which ranged from 58.8 to $66.6 \%^{6,10,28,29}$. Bigal et al. ${ }^{6}$ also detected an important proportion of severe $\mathrm{CA}$ in patients with migraine (28.5\% in transformed migraine and $20.4 \%$ in migraine) compared to other primary headaches.

According to the scores for the questions, the activities most frequently reported to provoke pain or discomfort

Table 2. Measurement properties of the questionnaire 12 item Allodynia Symptom Checklist/Brasil (ASC-12/Brasil).

\begin{tabular}{|c|c|c|c|c|c|c|}
\hline & \multirow[b]{2}{*}{ Activity } & \multirow[b]{2}{*}{ Domain } & \multirow{2}{*}{$\begin{array}{l}\text { Score } \\
(n=60)\end{array}$} & \multirow{2}{*}{$\begin{array}{c}\text { Internal } \\
\text { consistency } \\
\alpha \text { de Cronbach }\end{array}$} & \multicolumn{2}{|c|}{ Reproducibility $(n=15)$} \\
\hline & & & & & Weighted Kappa & $95 \% \mathrm{Cl}$ \\
\hline Question 1 & $\begin{array}{l}\text { Combing } \\
\text { one's hair }\end{array}$ & Dynamic & 66 & 0.72 & 0.65 & $0.38-0.92$ \\
\hline Question 2 & Tying one's hair & Dynamic & 63 & 0.74 & 0.81 & $0.53-1$ \\
\hline Question 3 & Shaving & Thermal & 1 & 0.80 & 1 & - \\
\hline Question 4 & Wearing glasses & Static & 11 & 0.74 & 0.58 & $0.31-0.85$ \\
\hline Question 5 & $\begin{array}{l}\text { Wearing contact } \\
\text { lenses }\end{array}$ & Static & 2 & 0.78 & 0.65 & $0.62-0.68$ \\
\hline Question 6 & Wearing earrings & Static & 12 & 0.73 & 0.63 & $0-1$ \\
\hline Question 7 & $\begin{array}{l}\text { Wearing a } \\
\text { necklace }\end{array}$ & Static & 14 & 0.74 & $\star$ & \\
\hline Question 8 & $\begin{array}{l}\text { Wearing tight- } \\
\text { fitting clothes }\end{array}$ & Static & 23 & 0.72 & 0.43 & $0-0.93$ \\
\hline Question 9 & Bathing & Thermal & 24 & 0.75 & 0.42 & $0-1$ \\
\hline Question 10 & $\begin{array}{c}\text { Resting one's face } \\
\text { on a pillow }\end{array}$ & Thermal & 61 & 0.73 & 0.72 & $0.43-1$ \\
\hline Question 11 & Exposure to heat & Thermal & 61 & 0.73 & 0.60 & $0.30-0.89$ \\
\hline Question 12 & Exposure to cold & Thermal & 26 & 0.73 & 0.58 & $0.29-0.86$ \\
\hline Total & - & - & - & 0.76 & 0.58 & $0.29-0.86$ \\
\hline
\end{tabular}

* It was not possible to calculate the reliability of Question 7 because all 15 individuals evaluated scored 0 (zero). Cl: Confidence interval.

Table 3. Characteristics of headache in the groups tested with the translated version 1 and the translated version 2 (TV2) and their associations with the scores of the 12 item Allodynia Symptom Checklist/Brasil (ASC-12/Brasil) according to the Fischer exact test.

\begin{tabular}{|c|c|c|c|c|c|}
\hline & \multicolumn{2}{|c|}{ TV 1} & \multicolumn{2}{|c|}{ TV 2} & \multirow{2}{*}{$\begin{array}{c}\text { Association with ASC-12/Brasil } \\
\text { p-value }\end{array}$} \\
\hline & Mean & SD & Mean & SD & \\
\hline Frequency of attacks (days/month) & 7.7 & 3.7 & 6.4 & 3.3 & 0.97 \\
\hline Time of disease (years) & 16.1 & 10 & 12.7 & 10.4 & 0.29 \\
\hline Pain during the attacks (VAS) & 8 & 1.9 & 8.1 & 1.9 & 0.10 \\
\hline \multirow[t]{2}{*}{ Pain at the time of evaluation (VAS) } & $(n=11)$ & & $(n=6)$ & & \\
\hline & 5.7 & 2 & 5 & 2.4 & 0.31 \\
\hline
\end{tabular}

VAS: visual analogue scale; SD: Standard deviation;TV1: translated version 1; TV2: translated version 2. 
were: combing one's hair (question1), tying one's hair (question 2), resting one's face on the pillows (question 10) and exposure to heat (question 11), indicating that the questionnaire can identify CA in all domains (static and dynamic mechanics and thermal mechanics). Its presence has been previously demonstrated in migraneurs using other methods for evaluation such as the $\mathrm{QST}^{30}$, brushing ${ }^{26}$ and Von Frey monofilaments ${ }^{30}$.

The ASC-12/Brasil showed good internal consistency (0.72-0.80), a fact that demonstrates the similarity of construct of the questions and no construct redundancy. Reproducibility was also acceptable for clinical practice since it was considered to be moderate to excellent. The maintenance of the self-reported administration and the changes made in the questionnaire format without influence on its reproducibility ensured the operational equivalence ${ }^{27}$.

The process of translation and cultural adaptation and the two psychometric characteristics tested guarantee the use of the ASC-12/Brasil as a reliable tool which facilitates the evaluation of $\mathrm{CA}$ in daily practice. Other measurement properties, such as concurrent validity, are currently being tested in order to demonstrate whether the sensitivity and specificity of the original questionnaire were maintained.

In conclusion, we made available to Brazilian population a rapid, practical and reliable tool for the evaluation of CA in clinical and epidemiological practice.

\section{References}

1. Loeser JD, Treede RD. The Kyoto protocol of IASP Basic Pain Terminology. Pain 2008;137:473-477.

2. Guy N, Marques AR, Orliaguet T, Lanteri-Minet M, Dallel R, Clavelou P. Are there differences between cephalic and extracephalic cutaneous allodynia in migraine patients? Cephalalgia 2010;30:881-886.

3. Burstein R, Cutrer M, Yarnitsky D. The development of cutaneous allodynia during a migraine attack. Clinical evidence of the sequential recruitment of spinal and supraspinal nociceptive neurons in migraine. Brain 2000;123:1703-1709.

4. Cuadrado ML, Young WB, Fernández-de-las-Peñas C, Arias JA, Pareja JA. Migraneous corpalgia: body pain and allodynia associated with migraine attacks. Cephalalgia 2008;28:87-91.

5. Dodick D, Silberstein S. Central sensitization theory of migraine: clinical implications. Headache 2006;46(Suppl):S182-S191.

6. Bigal ME, Ashina S, Burstein R, et al. Prevalence and characteristics of allodynia in headache sufferers: a population study. Neurology 2008;70:1525-1533

7. Filatova E, Latysheva N, Kurenkov A. Evidence of persistent central sensitization in chronic headaches: a multi-method study.J Headache Pain 2008;9:295-300.

8. Lovati C, D’Amico D, Bertora P. Allodynia in migraine: frequent random association or unavoidable consequence? Expert Rev Neurother 2009;9:395-408.

9. Tietjen GE, Brandes JL, Peterlin BL, et al. Allodynia in migraine: association with comorbid pain conditions. Headache 2009;49: 1333-1344.

10. Lipton RB, Bigal ME, Ashina S, et al. Cutaneous allodynia in the migraine population. Ann Neurol 2008;63:148-158.

11. Bevilaqua-Grossi D, Lipton RB, Napchan U, Grosberg B, Ashina, Bigal ME. Temporomandibular disorders and cutaneous allodynia are associated in individuals with migraine. Cephalalgia 2010;30: 425-432.

12. Burstein $\mathrm{R}$, Collins $\mathrm{B}$, Jakubowski $\mathrm{M}$. Defeating migraine pain with triptans: a race against the development of cutaneous allodynia. Ann Neurol 2004;55:19-26.

13. Hansson P, Backonja M, Bouhassira D. Usefulness and limitations of quantitative sensory testing: clinical and research application in neuropathic pain states. Pain 2007;129:256-259.

14. Jääskeläinen SK. Clinical neurophysiology and quantitative sensory testing in the investigation of orofacial pain and sensory function. $J$ Orofac Pain 2004;18:85-107.

15. Jakubowski M, Silberstein S, Ashkenazi A, Burstein R. Can allodynic migraine patients be identified interictally using a questionnaire? Neurology 2005;65:1419-1422.
16. Queiroz LP, Peres MF, Piovesan EJ, et al. A nationwide populationbased study of migraine in Brazil. Cephalalgia 2009;29:642-649.

17. Guillemin F, Bombardier C, Beaton D. Cross-cultural adaptation of health-related quality of life measures: literature review and proposed guidelines. J Clin Epidemiol 1993;46:1417-1432.

18. Peters $M$, Passchier J. Translating instruments for crosscultural studies in headache research. Headache 2006;46:82-91.

19. Ware JE Jr, Gandek B. Methods for testing data quality, scaling assumptions, and reliability: the IQOLA Project approach. International Quality of Life Assessment. J Clin Epidemiol 1998;51: 945-952.

20. Beaton DE, Bombardier C, Guillemin F, Ferraz MB. Guidelines for the process of cross-cultural adaptation of self-report measures. Spine 2000;25:3186-3191.

21. Mokkink LB, Terwee CB, Patrick DL, et al. The COSMIN study reached international consensus on taxonomy, terminology, and definitions of measurement properties for health-related patient-reported outcomes. J Clin Epidemiol 2010;63:737-745.

22. Terwee CB, Bot SDM, de Boer MR, et al. Quality criteria were proposed for measurement properties of health status questionnaires. J Clin Epidemiol 2007;60:34-42.

23. de Vet HCW, Terwee CB, Knol DL, Bouter LM. When to use agreement versus reliability measures. J Clin Epidemiol 2006;59:1033-1039.

24. Landis JR, Koch GG. The measurement of observer agreement for categorical data. Biometrics 1977;33:159-174.

25. Marodim G, Goldim JR. Confusões e ambiguidades na classificação de eventos adversos em pesquisa clínica. Rev Esc Enferm USP 2009;43:690-696.

26. Wild D, Grove A, Martin M, et al. Principles of good practice for the translation and cultural adaptation process for patientreported outcomes (PRO) measures: report of the ISPOR Task Force for translation and cultural adaptation. Value Health 2005;8: 94-104.

27. Hilton A, Skrutowski M. Translating instruments into other languages: development and testing processes. Cancer Nurs 2002;25:1-7.

28. Chou CH, Fuh JL, Wu JC, Wang SJ. Comparison of self-reported cutaneous allodynia and brushing allodynia during migraine attacks. Cephalalgia 2010;30:682-685.

29. Zapaterra M, Guerzoni S, Cainazzo MM, Ferrari A, Pini LA. Basal cutaneous pain threshold in headache patients. J Headache Pain 2011:12:303-310.

30. Schwedt TJ, Krauss MJ, Frey K, Gereau RW. Episodic and chronic migraineurs are hypersensitive to thermal stimuli between migraine attacks. Cephalalgia 2011;31:6-12. 